\section{Do we need a running line for administration of vasopressors through the multi-Iumen central venous catheter during neurosurgical cases?}

\section{Sir,}

Administration of anaesthetic agents causes massive vasodilatation. This vasodilatory effect is more profound in patients who are hypovolemic, hypertensive and in patients with autonomic dysfunction. Despite filling patients with adequate fluids, they still hypotense; hence, it is very common to administer a low dose of vasopressors (noradrenaline $0.025-0.05 \mu \mathrm{g} / \mathrm{kg} / \mathrm{min}$ ) to maintain the blood pressure within acceptable normal limits during surgery. We routinely administer a running fluid when vasopressors are connected through the peripherally inserted central venous catheter (line) because of its long length and its dead space. However, for the triple-lumen catheter, we directly connect the vasopressor line without the running line because of its proximity to the vein and its minimal dead space.

In the past, we have had three to four cases where the lumen got occluded during the middle of surgery and the blood pressure did not come up despite increasing the rate of noradrenaline. The syringe infusion pump (Terumo Terufusion $^{\circledast}$ TE-331) also showed an occlusion detection pressure at $3^{\text {rd }}$ level $(800 \pm 200 \mathrm{mmHg})$ [Figure $1 \mathrm{~b}$ ]. Line

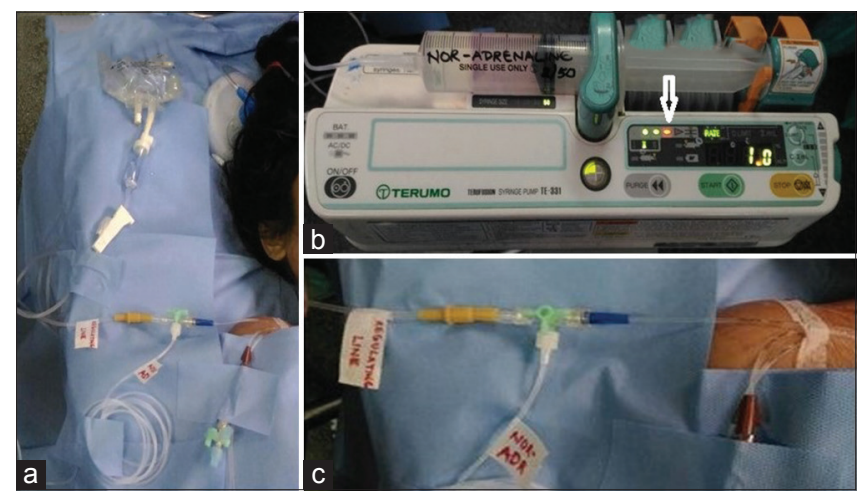

Figure 1: (a) The set-up of running line for noradrenaline infusion. (b) Arrow showing the occlusion pressure at the $3^{\text {rd }}$ level when the infusion is running at $1 \mathrm{ml} / \mathrm{h}$. (c) Closer view of noradrenaline line connected to the side port of 3-way with the running line occlusion was also confirmed by the inability to aspirate blood from that lumen. Since flushing the line will cause a purge of vasopressor from the dead space, we had disconnected that line and connected it to the proximal lumen with a running line. In few other cases, where the vasopressor was running without showing occlusion pressure during surgery, however, we were not able to aspirate the blood to remove the noradrenaline from the dead space at the end of surgery. All these cases we had flushed that line after giving a bolus of propofol $(20 \mathrm{mg})$ and glyceryl trinitrate $(60 \mu \mathrm{g})$ to counteract the effect of noradrenaline at the end of surgery. Increasing the blood pressure above the baseline blood pressure at the end of case can disrupt haemostasis and cause life-threatening post-operative haematoma formation, especially in neurosurgical cases.

In most neurosurgical cases, the head end is away from the anaesthetist, so checking the patency or changing the vasopressor line during surgery is very difficult and requires going under the drapes. We recommend a running line for the vasopressor line, especially when we are not using the micro-infusion pump which can deliver the minimum amount of $0.01 \mathrm{ml} / \mathrm{h}$. If we are using a running line, it has to be regulated to keep the running fluid at the rate of 15-30 drops/min which will deliver about $1-2 \mathrm{ml} / \mathrm{min}$ or $60-120 \mathrm{ml} / \mathrm{h}$. By this means, when we alter the vasopressor dose, the desired dose will reach the patient quickly. At the end of the case, once the vasopressor is stopped, all the vasopressor in the dead space will automatically be flushed by the running line gradually and the need to aspirate the line does not arise. Aspirating the blood can cause for intraluminal thrombus formation and can lead to catheter occlusion which can be avoided. Depending on the duration of the case, we can select the volume of the running fluid bag as 500 or $1000 \mathrm{ml}$ so that we do not need to change the bag during the case. Figure 1a and c shows the running line for infusing the vasopressor during the neurosurgical case. If a $100 \mathrm{~cm}$ extension is connected to the running line (to keep the intravenous [IV] stand away from the surgical field), its 3-way needs to be sealed off to avoid accidental injection of drugs through this line which can be detrimental to the patient.

Catheter occlusion is the most common complication of central venous catheter insertion and its incidence is up to $36 \%{ }^{[1,2]}$ Fibrin formation is a natural process that may occur soon after insertion of a device or may develop at any time during IV therapy. This fibrin sheath can partially or fully occlude the lumen. When we administer inotropes or vasopressors at a low rate, it takes a long time to show this occlusion pressure on the syringe pump. Furthermore, it is possible that as the line pressure 
builds up, that pressure itself can dislodge the fibrin clot and can cause purging of a vasopressor which can be detrimental. We therefore recommend that a running line always is connected to the vasopressor lumen, especially if vasopressors need to be given at a low infusion rate.

\section{Financial support and sponsorship}

Nil.

\section{Conflicts of interest}

There are no conflicts of interest.

\section{Ramamani Mariappan, Leah R. George, Tina Vaz}

\author{
Department of Anaesthesia, Christian Medical College, \\ Vellore, Tamil Nadu, India \\ Address for correspondence: \\ Dr. Ramamani Mariappan, \\ Department of Anaesthesia, Christian Medical College, \\ Vellore, Tamil Nadu, India.
} E-mail: ramamani@cmcvellore.ac.in

\section{REFERENCES}

1. Napalkov P, Felici DM, Chu LK, Jacobs JR, Begelman SM. Incidence of catheter-related complications in patients with central venous or hemodialysis catheters: A health care claims database analysis. BMC Cardiovasc Disord 2013;13:86.

2. Baskin JL, Pui CH, Reiss U, Wilimas JA, Metzger ML, Ribeiro RC, et al. Management of occlusion and thrombosis associated with long-term indwelling central venous catheters. Lancet 2009;374:159-69.

This is an open access article distributed under the terms of the Creative Commons Attribution-NonCommercial-ShareAlike 3.0 License, which allows others to remix, tweak, and build upon the work non-commercially, as long as the author is credited and the new creations are licensed under the identical terms.

\begin{tabular}{|l|l|}
\hline \multicolumn{2}{|c|}{ Access this article online } \\
\hline Quick Response Code: & Website: \\
\hline & www.jnaccjournal.org \\
\cline { 2 - 2 } & \\
\hline
\end{tabular}

How to cite this article: Mariappan R, George LR, Vaz T. Do we need a running line for administration of vasopressors through the multi-lumen central venous catheter during neurosurgical cases?. J Neuroanaesthesiol Crit Care 2017;4:59-60. 